\title{
A New Fuzzy Based UPFC Topology for Active Power Enhancement in an offshore Wind Farm
}

\author{
Dhanvanti Rathore \\ M.Tech Scholar \\ Scope College of Engineering \\ Bhopal, Madhya Pradesh, India \\ dhanvi421@gmail.com
}

\author{
N K Singh \\ Assistant Professor \\ Scope College of Engineering \\ Bhopal, Madhya Pradesh, India \\ dannyk0809@gmail.com
}

\begin{abstract}
The stability of a power system is the ability of a power system to restore an operating state of equilibrium for a given initial operating condition after it has been subjected to a physical disturbance, most of the variables of the system being limited so that almost the entire system remains intact. To create a MATLAB SIMULINK model of odd shore wind energy system having power being transmitted through DC transmission system. The first model will have no power flow controller and second model will have artificial intelligence based controlling technique. To design a controller for enhancing the power output from the wind energy system using UPFC. This will be made to feed DC transmission system. Finally integrating the system with long distance DC transmission system and then to the grid so as to make it more reliable and efficient. In this work a coordinated control based on Fuzzy logic for UPFC for cluster of offshore WPP connected to the same HVDC connection is being implemented and analyzed. The study is targeting coordination of reactive power flow and active power flow between HVDC Converter and the WPP cluster while providing offshore AC grid voltage control. Thus it can be drawn from this work that while designing a power control strategy the proposed fuzzy logic based active power controller in UPFC can serve the purpose with better results in terms of active as well as reactive power. This control can also be used in hybrid systems thus making it more reliable controlling method. The system designed is also fitted to feed the nonlinear load.
\end{abstract}

Keywords: FACT device, AC-DC convertor, DFIG, wind.

\section{INTRODUCTION}

Power system stability is the ability of a power system to return to an operating equilibrium state under certain operating conditions after a physical disturbance, with most system variables so limited that virtually the entire system remains intact [1]. It is a complex problem that can be influenced by a variety of factors and represented by different forms. Due to several key considerations, the power system stability problem can be divided into several classes. Conventional power systems rely on synchronous generators for power supply and the stability of power systems is therefore mainly determined by these synchronous machines. However, wind energy conversion systems have very different dynamic properties from conventional power generation units. With the increasing penetration of wind energy and the integration of large wind farms, energy systems will undoubtedly undergo significant changes in their structures and operations as conventional power plants gradually go out of service.

\section{LITERATURE REVIEW}

Gang Shi et al. [1] This study shows that DC wind farm (DCWF) with series connected DC wind turbines (DCWT) represents a possible solution for offshore wind power generation. The coupling behavior of series-connected DCWTs is described in detail. A possible limitation of wind energy when limiting the wind farm voltage and its most important influencing factors are first calculated quantitatively. If DCWT voltage limiting affects the energy storage system (ESS) support, a decoupling control strategy is proposed to improve wind energy sensing. This control algorithm is often implemented in the local DCWT controller without communication.

Jianwen Zhang et al. [2] This revision of the control algorithm is often implemented on the local DCWT controller without requiring communication. The exact DCWT strategy for variable speed control is implemented during a generalized averaging model. Dynamic simulation cases were performed under different operating conditions to measure the effectiveness of the proposed control strategy. The coupling behavior of seriesconnected DCWTs is described in detail. A possible limitation of wind energy when limiting the wind farm voltage and its most important influencing factors are first calculated quantitatively. Under DCWT voltage limiting conditions, a variable speed control override strategy is proposed to improve wind energy detection. 
Etienne Veilleux et al. [3] This text contains a "distributed DC / DC converter" for offshore wind farms. The proposed converter topology allows series connection of wind turbines without an AC transformer or offshore platform at the end of the transmission. Each turbine is equipped with a $5 \mathrm{MW}$ synchronous generator with static magnet and an AC / DC converter. An entire wind farm is simulated with the PSCAD / EMTDC software package. The $150 \mathrm{MW}$ wind farm is modeled with six $25 \mathrm{MW}$ units with an intermediate circuit voltage rating of $125 \mathrm{kV}$ to $1.2 \mathrm{kA}$. The simulation shows the stable operation of the proposed configuration, where each turbine can independently monitor the performance at altitude.

Van-Tung Phan et al [4] studied the control of an independent wind energy conversion system that supports DFIG with unbalanced and non-linear loads. The proposed compensation method is based on current controllers within the RSC or GSC that used a proportional integral plus a resonance controller. It describes the analytical problems as it is possible to eliminate the asymmetrical and distorted components of the stator voltage and therefore the voltage factor of the stator.

\section{OBJECTIVE}

- To create a MATLAB SIMULINK model of off shore wind energy system having power being transmitted through DC transmission system. The first model will have no power flow controller and second model will have artificial intelligence based controlling technique.

- The AI techniques are most common in recent years as controlling algorithms. The effort is to be made to integrate it with the FACT device and improve its output capability.

- To design a controller for enhancing the power output from the wind energy system using UPFC. This will be made to feed DC transmission system. This type of transmission system is preferred for long distance power transfer due to less losses.

- The fuzzy logic set of rules is to be implemented for controlling the power enhancement device off the DCWT system. The fuzzy rules are implemented to govern the power output from the power enhancement device such that the output power is improved.

- Finally integrating the system with long distance DC transmission system and then to the grid so as to make it more reliable and efficient.

- The DCWT system is developed such that it can be used for driving various kinds of loads.

IV. Methodology
The model was developed in a MALAB / SIMULINK environment. It is a high-level matrix / array language with control flow instructions, functions, data structures, input / outputs and object-oriented programming functions. It has the following main features:

- High level language for scientific and technical elaboration

- Office environment for iterative exploration, design and troubleshooting

- Charts to view data and tools to create custom charts

- Applications for curve adaptation, data classification, signal analysis, control system control and many other activities

- Additional tool boxes for a variety of technical and scientific applications

- Tools for creating applications with customized user interfaces

- Royalty-free deployment options for sharing MATLAB programs with end users

The modeling of Dual Voltage Source Inverter system is done which is capable of feeding the load with either solar or wind resources depending on the availability thus making the system more reliable.

\section{A. wind energy system modeling}

The model of a wind turbine with PMSG wind turbines is unable to fully record wind energy. The components of the wind turbine were modeled using the following equations.

Output aerodynamic power of the wind-turbine is expressed as:

$$
P_{\text {Turbine }}=\frac{1}{2} \rho A C_{p}(\lambda, \beta) v^{3}
$$

Where, $\rho$ is the air density (typically $1.225 \mathrm{~kg} / \mathrm{m} 3$ ), $A$ is the area swept by the rotor blades (in $\mathrm{m} 2$ ), $C P$ is the coefficient of power conversion and $v$ is the wind speed (in $\mathrm{m} / \mathrm{s}$ ).

The tip-speed ratio is defined as:

$$
\lambda=\frac{\omega_{m} R}{v}
$$

Where $\omega_{m}$ and $R$ are the rotor angular velocity (in $\mathrm{rad} / \mathrm{sec}$ ) and rotor radium (in $\mathrm{m}$ ), respectively.

The wind turbine mechanical torque output $m T$ given as:

$$
T_{m}=\frac{1}{2} \rho A C_{p}(\lambda, \beta) v^{3} \frac{1}{\omega_{m}}
$$

The power coefficient is a nonlinear function of the tipspeed ratio $\lambda$ and the blade pitch angle $\beta$ (in degrees).

Then Power output is given by

$$
P_{\text {Turbine }}=\frac{1}{2} \rho A C_{p_{\max }} v^{3}
$$


A generic equation is used to model the power coefficient $C_{P}$ based on the modeling turbine characteristics described in [2], [7-9] and [11] as:

$$
C_{p}=\frac{1}{2}\left(\frac{116}{\lambda_{i}}-0.4 \beta-5\right) e^{-\left(\frac{21}{\lambda_{i}}\right)}
$$

For each wind speed, there is a specific point in the wind energy curve, MPPT, where the output power is maximized. The WECS load control then operates the turbine rotor at variable speed, so that maximum power is continuously withdrawn from the wind.

This mechanism uses the variable torque output when trying to optimize the current waveform and the output voltage to its maximum value.

\section{B. UPFC Working}

UPFC consists of two back to back GTO based voltage source converters (shunt and series) via a common DC link as shown in Fig.1. The main objective of series converter is to produce an ac voltage $\mathrm{Vc}$ of controllable magnitude and phase angle and inject this voltage at the fundamental frequency in series with the transmission line, exchanging the real and reactive powers at its ac terminals through the series connected transformers.

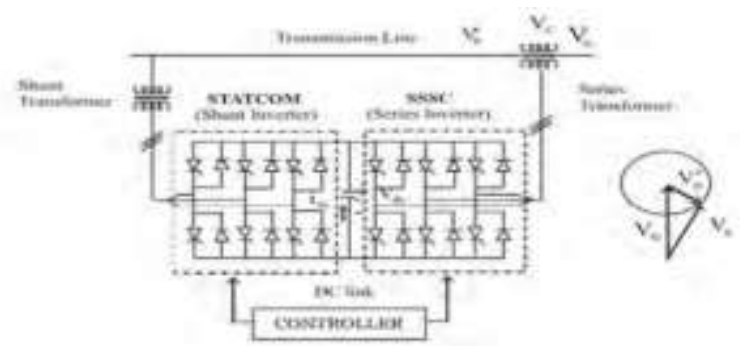

Fig. 1. Basic Circuit Configuration of the Unified Power Flow Controller.

The shunt converter regulates the real power or it controls the capacitor's DC voltage by providing the required real power at the DC terminals. It also provides the voltage regulation of the shunt connected point through adjusting reactive power (generating or absorbing the reactive power). The two converters can generate or absorb the power independently without flowing through the DC link. Thus, UPFC can fulfill the functions of reactive shunt compensation, series compensation and phase shifting and meet multiple control objectives by adding the voltage $\mathrm{Vc}$ with appropriate amplitude and phase angle to the terminal voltage $\mathrm{Vu}$.

The power system is composed of a synchronous machine connected to the grid via a transmission line. The UPFC is connected to the bus near the machine and its model is given as ideal transformer model. The power system model including UPFC is also shown in Fig. 2.

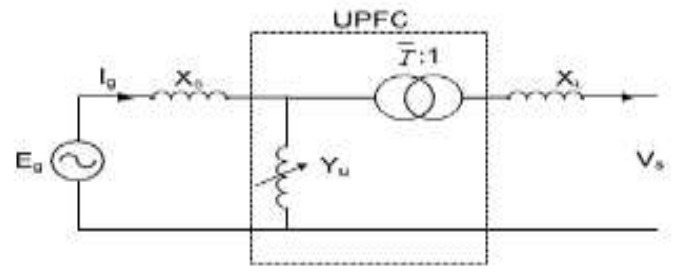

Fig. 2. Power system model including UPFC

$M_{\mathrm{dt}}^{\frac{\mathrm{dO} \omega}{\mathrm{dt}}}=\mathrm{P}_{\mathrm{m}}-\mathrm{P}_{\mathrm{g}}-\mathrm{D}^{\frac{\mathrm{d} 6}{\mathrm{dt}}}$

Where

M: $\quad$ Momentum of rotor

Pm: Input mechanical power

Pg: $\quad$ Output generator power

D: $\quad$ Friction coefficient

$\omega$ : $\quad$ Rotor speed

$\delta$ : $\quad$ Load angle

It is necessary to calculate $\mathrm{Pg}$ based on UPFC and network parameters. Pg is Eg times Ig, therefore current generator must be calculated.

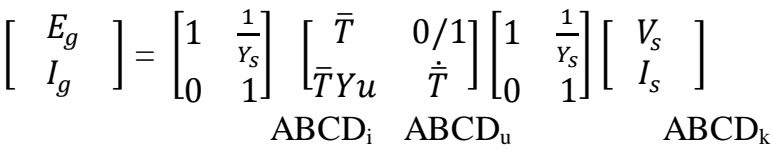

Eg: Internal voltage of generator

ABCD: Transmission matrix

T: $\quad$ Complex ratio of transformer

Yu: $\quad$ UPFC admittance

Ys: Generator admittance

YL: $\quad$ Line admittance

Equation (2) can be written as (3).

$\left[\begin{array}{l}E_{g} \\ I_{g}\end{array}\right]=\left[\begin{array}{ll}A & B \\ C & D\end{array}\right]\left[\begin{array}{l}V_{s} \\ I_{S}\end{array}\right]$

$\mathrm{A}=\frac{\bar{T} Y_{S}+\bar{T} Y_{u}}{Y_{S}}$

$\mathrm{B}=\frac{\left.|| \bar{T}\right|^{2} Y_{S}+|\bar{T}|^{2} Y_{u}+Y_{L} \mid}{\dot{T} Y_{L} Y_{S}}$

$\mathrm{C}=\bar{T} Y_{u}$

$\mathrm{D}=\frac{\left.|| \bar{T}\right|^{2} Y_{u}+Y_{L} \mid}{\dot{\bar{T}} Y_{L}}$

And generator current is:

$\mathrm{I}_{\mathrm{g}}=V_{s}\left(C-\frac{D A}{B}\right)+\frac{D}{B} E_{g}$

The basic modeling of the UPFC is done in the manner stated above by utilizing the equations.

The UPFC is being created in the model as shown below 


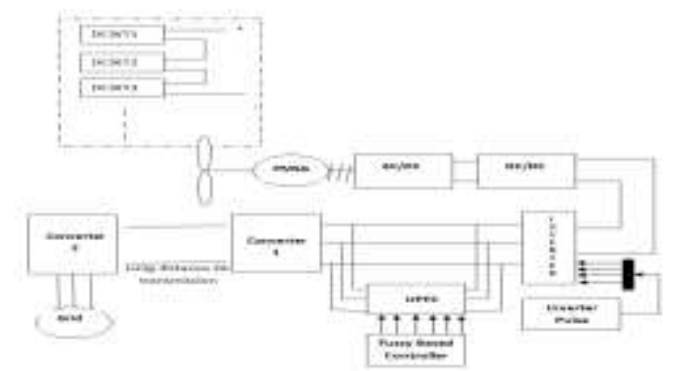

Fig. 3 Long Distance DC transmission of Wind turbine system

Wind turbines come with different topologies, architectures and design features. The schematic of a wind turbine generation system is shown in Fig. 3 The DCWT system is composed of the various wind turbines connected together in parallel connection. A cluster composed of four series-connected DCWTS is still taken as an example and its dynamic behavior with wind power variation. The power enhancement device is controlled via a fuzzy based controller for generating pulses for the device. Study of an offshore wind farm with HVDC transmission for grid connection, where the wind turbines in the offshore wind farm are also connected with dc collection network.

\section{Fuzzy based UPFC}

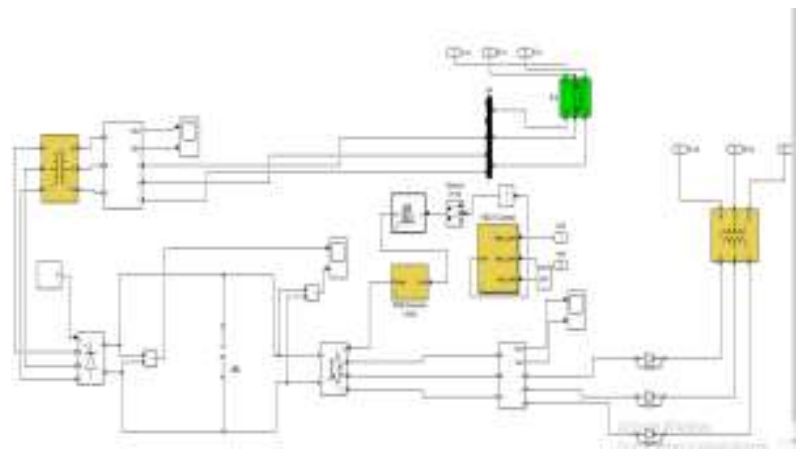

Fig.4 Fuzzy logic based power enhancement device

The power enhancement devices consist of combination of series and shunt transformer. It employs two converters having a DC link. The second converter output is optimized by using a fuzzy logic controller as shown in figure.

The output AC voltage from the system and current is taken as input to the voltage source controller. It generates a reference value for the pulse generation in order to control the voltage and improve the active power generated. The reference generated is further taken as input to the fuzzy based controller that traces the optimum power output by comparing the initial output and generating a second reference value for PWM generator. The pulse so obtained is fed to the converter of power enhancement device.
Fuzzy logic is based on the concept of deciding output based on hypotheses. It works on a quantitative basis. Each sentence represents a language variable that defines the possible state of the output. Each possible entry state and degrees of state change are part of the package, depending on the expected exit. It basically works on the If-else-the principle, i. H. If A AND B, then $\mathrm{Z}$.

Suppose we want to control a system where the output can be anywhere in the set $\mathrm{X}$ with a generic value $\mathrm{x}$ such that $\mathrm{x}$ belongs to $\mathrm{X}$. Consider a certain set $\mathrm{A}$, which is a subset of $\mathrm{X}$, to which all members of $A$ they belong to the range 0 and 1 . Set $A$ is known as fuzzy set and the value of fA (x) in $x$ indicates the degree of membership of $x$ in this set. The output is decided based on the degree of belonging to $\mathrm{x}$ as a whole. This membership assignment depends on the acceptance of the outputs based on the inputs and the speed at which the inputs are changed.

Each fuzzy logic block is made up of two inputs and one output. The first entry is the error and the other entry is the error rate, which is sampled once before the error values. The input and output membership functions are similarly named for all the transmission line parameters. The conventional controller is replaced by a fuzzy controller. The input variables for the fuzzy controller are the error signal and the modification of this error.

The following seven fuzzy levels are chosen for each input and output variables as NB (-ve Big), NM (-ve medium), NS (-ve Small), Z (zero), PL (+ve low), PM (+ve medium), and PH (+ve high).

Table 1 shows the rules formed on the basis of the fact that control output should be high and low error. Figure 5-7 shows the input variables and output variable membership functions.

Table 1 Fuzzy Rule Table for UPFC

\begin{tabular}{|l|l|l|l|l|l|l|l|}
\hline error/coe & NM & NS & Z & PL & PM & NB & PH \\
\hline NM & NH & NH & NH & NL & PH & NH & PL \\
\hline NS & NM & NL & PL & Z & PL & NH & PM \\
\hline Z & NL & NH & NL & PL & PM & NH & PH \\
\hline PL & NL & Z & PM & PM & PH & NM & PH \\
\hline PM & Z & PL & NM & PH & Z & NL & PH \\
\hline NB & NH & NH & Z & NM & NL & NH & Z \\
\hline
\end{tabular}




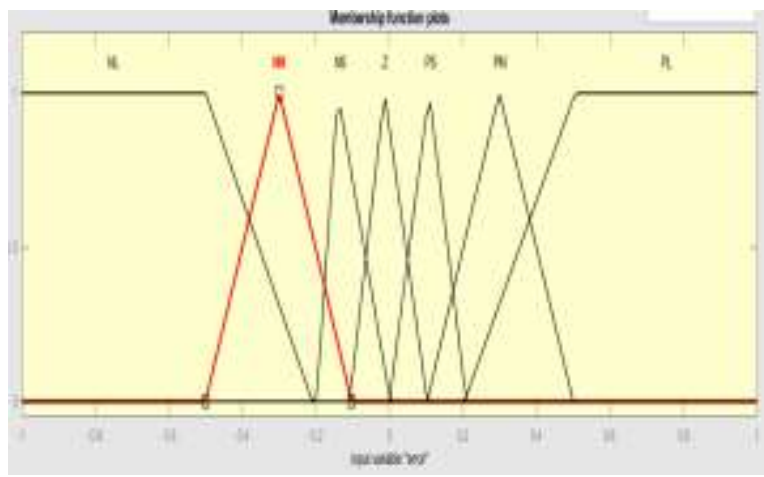

Fig. 5 Input Variable (error) Normalized Membership Function

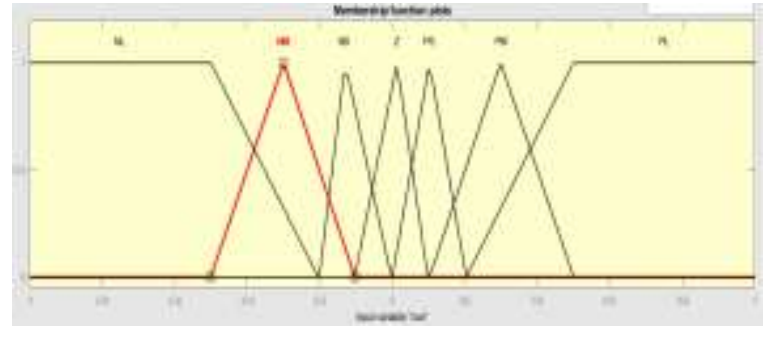

Fig. 6 Input Variable (coe) Normalized Membership Function

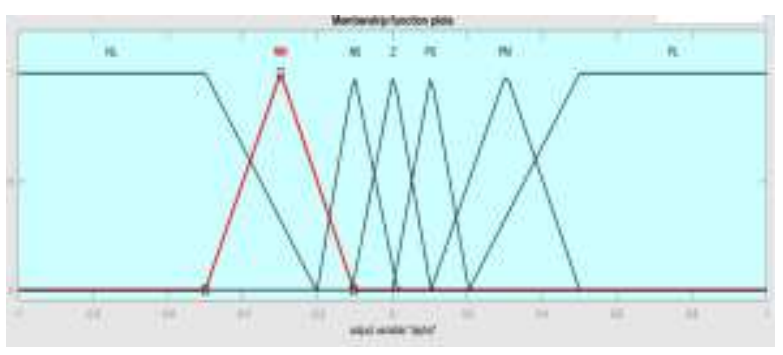

Fig. 7 Output Variable Normalized Membership Function

Simulation is carried out for a fixed RES generation, which is greater than the load demand. The result of both scenarios are compared.

\section{RESULTS}

Simulation means to imitate the actual environment moving in the direction of advantages of the research. Simulation can actually help the user or researcher to analyze their proposed design or existing algorithms. Simulation is important before the actual system is constructed because it checks the efficiency and the good quality of the design. Simulation is beneficial for the users, because they can search the advantages of that design many times. This can actually minimize the cost to reconstruct the changes have been done during design time.

Simulation technique can give large number of benefits as the experiments can be to do work as ordered with large amount of data in distinct abstraction level. Simulators can easily to create available different kind of virtual conditions for verification and performance to form an idea of the worth of the experimented system.

Power transmission systems based on HVDC technologies are foreseen as one of the key elements in future power systems including offshore grids. As each station is equipped with electronic interfaces, the behavior of HVDC networks is dominated by the control strategies. To evaluate the proposed control strategy, the average model of 5MW DCWT is implemented in MATLAB/SIMULINK.

\section{A. Implementation Details}

In this work a coordinated control based on Fuzzy logic for UPFC for cluster of offshore WPPs connected to the same HVDC connection is being implemented and analyzed. The study is targeting coordination of reactive power flow and active power flow between HVDC

Converter and the WPP cluster while providing offshore AC grid voltage control. The chapter discusses the results in two following cases:

Case 1: Offshore wind energy system integrated with the grid without any power controller

Case 2: Offshore wind energy system integrated with the grid having power enhancement fuzzy based controller

The wind speed of each DCWT is random wind speed with the average value of $12 \mathrm{~m} / \mathrm{s}$. The simulation is also made to adjust the speed variations from 0 to $12 \mathrm{~m} / \mathrm{s}$. The three phase output of the wind system is transferred to the long distance via DC transmission system.

\section{B. Modelled offshore wind energy system}

The modeling of wind energy system has been done using a permanent magnet synchronous machine (PMSG) which is used to convert the mechanical torque into three phase electrical power. The output is varied due to variations in wind speed from 0 to $12 \mathrm{~m} / \mathrm{s}$. The three phase output voltage is converted into DC using a rectifier. The DC output from the wind energy system is shown in figure 5.1.

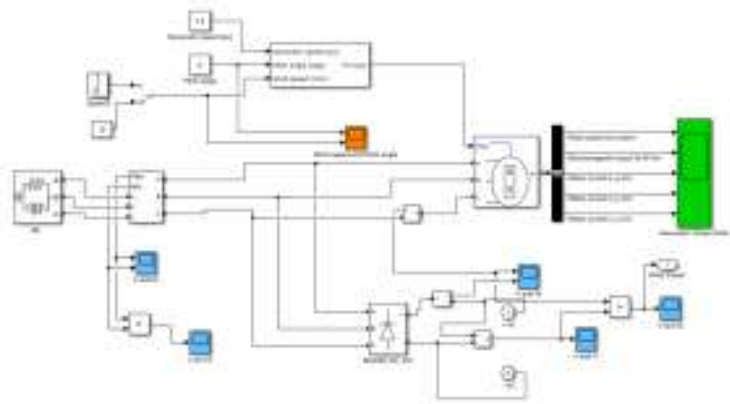

Fig. 8 The MATLAB/SIMULINK model of wind energy system The modeled wind energy system has following parameters which are being used are mentioned in the table below 
Table 2: Wind Turbine Parameters

\begin{tabular}{|l|l|}
\hline \multicolumn{1}{|c|}{ Parameters } & \multicolumn{1}{c|}{ Values } \\
\hline Rotor diameter & $126 \mathrm{~m}$ \\
\hline Rotating Speed & $4-11.9 \mathrm{rpm}$ \\
\hline Nominal Wind Speed & $11.4 \mathrm{~m} / \mathrm{s}$ \\
\hline Generator rated power & $5 \mathrm{MW}$ \\
\hline Number of poles & 100 \\
\hline Stator winding resistance & $0.001 \mathrm{ohms}$ \\
\hline Unsaturated inductance & $0.15 \mathrm{p.u}$ \\
\hline Generator inertia & $0.84 \mathrm{~s}$ \\
\hline Magnetic Strength & $1 \mathrm{p.u}$. \\
\hline Wind turbine inertia & $5.54 \mathrm{~s}$ \\
\hline Line voltage & $2.5 \mathrm{KV}$ \\
\hline
\end{tabular}

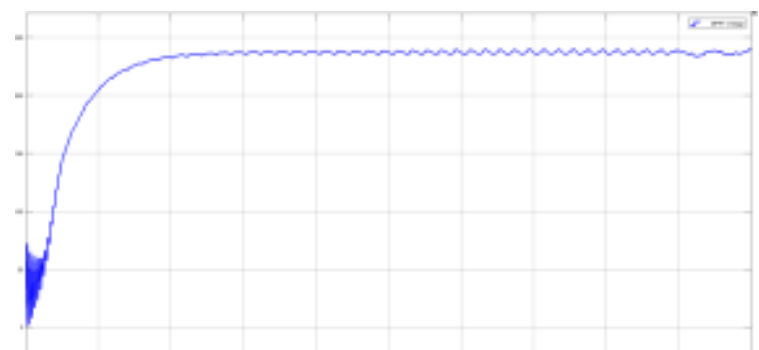

Fig. 9 DC output from the wind energy system after rectification The wind energy system gives approximately 200 volts DC output after it is being rectified. This output is then given to the inverter which converts it to three phase AC output and is then given to long distance DC transmission grid.
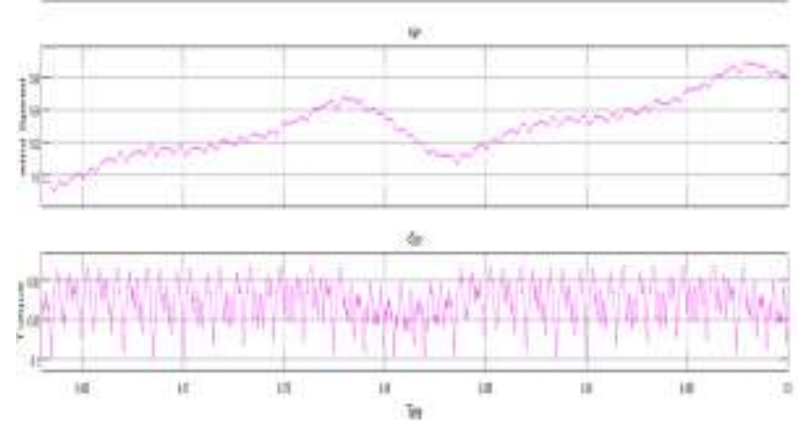

Fig. 10 Wind Speed and Corresponding Torque output from the turbine

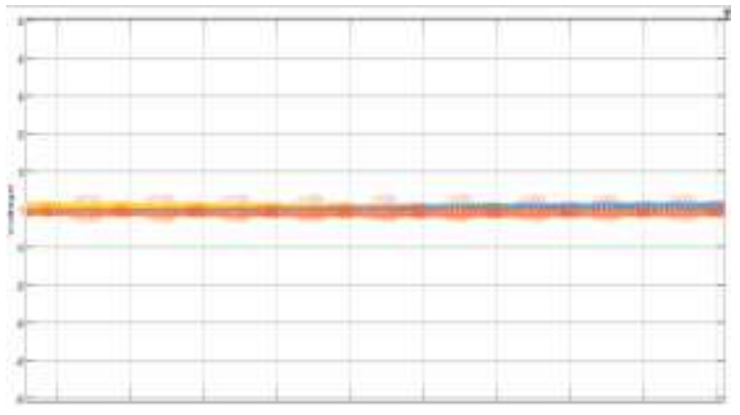

Fig. 11 Voltage output from DCWT (p.u)

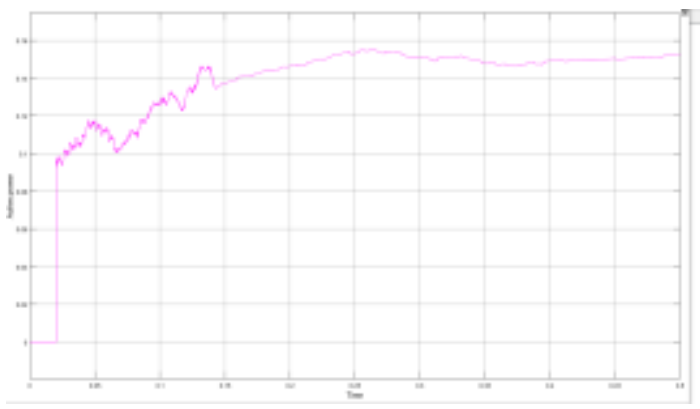

Fig. 12 Active power output from DCWT (p.u)

The graph shows the Active power output from DC wind turbine in per unit. The power output is approximately 0.5 per unit.

Case 1: Offshore wind energy system integrated with the grid without any power controller.

The inverter converts the DC output from the wind energy system using a control system. This gives us three phase AC output and this output is then given to long distance DC transmission line. DC transmission is the most economical solution compared to high-voltage AC. The challenge, however, is that to transmit via HVDC, two converter stations are needed. First, the AC power must be converted to DC to begin the transmission process, and then when it gets to the desired tie-in destination, the DC power must be converted back to $\mathrm{AC}$ to be utilized on the grid. Hence the model uses two power converter stations which is used to convert AC to DC and then from DC to $\mathrm{AC}$ in the place where load has to be driven.

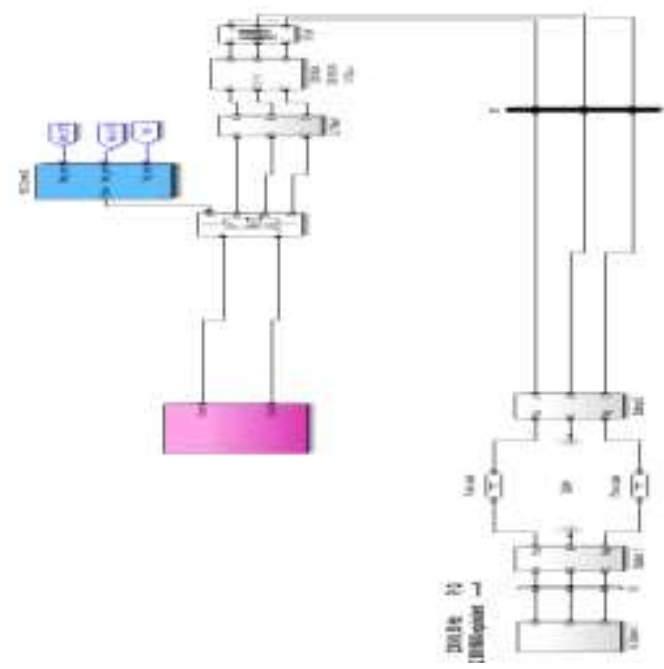

Fig. 13 Offshore wind energy system integrated with the grid without any power controller

In this system the AC side waveform is not affected by any kind of power enhancement device and controller. The AC power is generated in the generating station. This should first be converted into DC. The conversion is done with the help of rectifier. The DC power will flow through the overhead lines. At 
the user end, this DC has to be converted into AC. For that purpose, an inverter is placed at the receiving end. The figures below show the voltage, current, power output from this energy system.

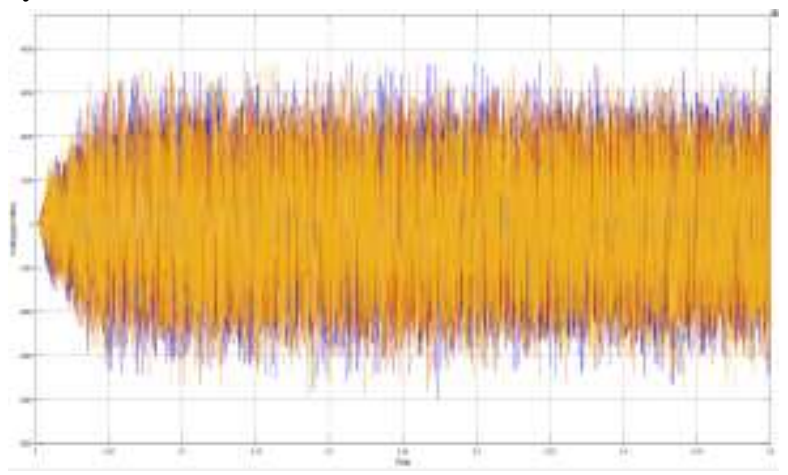

Fig. 14 Voltage Output of the system without using power controller

In this Wind energy system in which no power controller devices connected the voltage output is approximately $2.5 \mathrm{KV}$. This voltage output is from the system in which numerous DC wind turbine integrated and their voltage output is measured.

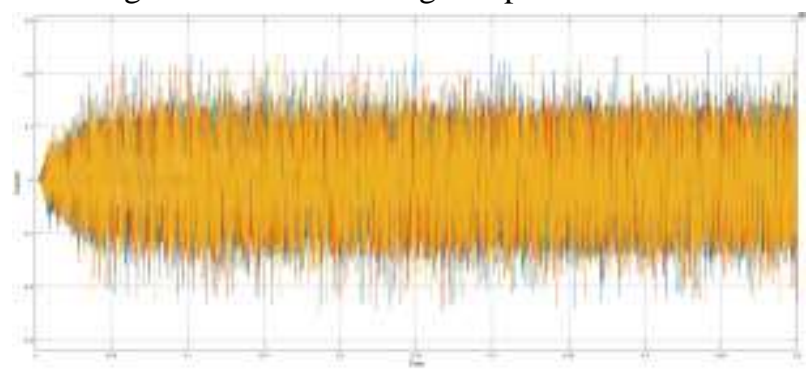

Fig. 15 Current Output of the system without using power controller

Fig. 15 is showing current output from the DC wind turbine at the point where the power is converted from $\mathrm{DC}$ to AC through inverter. The current is generated at 50 hertz which can be used for driving various kinds of loads at this point.

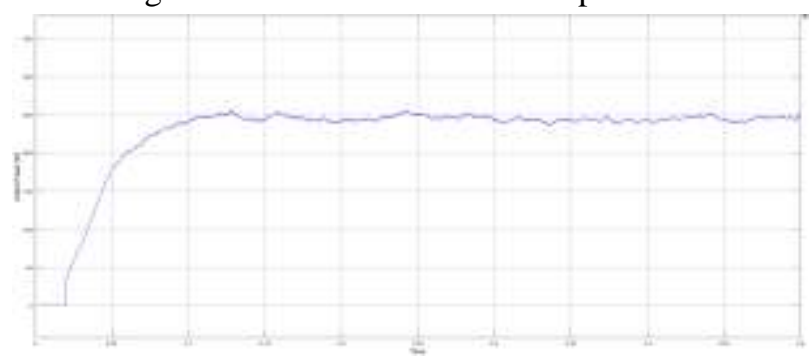

Fig. 16 Active Power Output of the system without using power controller

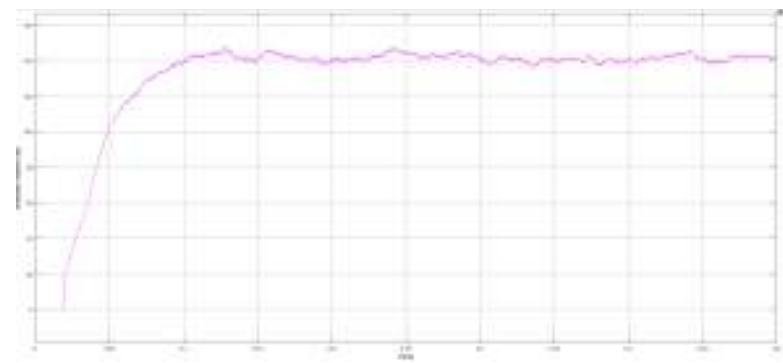

Fig.17 Reactive Power Output of the system without using power controller

The reactive power moves between the source and load of the circuit. Stability and reliability of electrical power system depends on reactive power management. The reactive power output from the DCWT system was found to be approximately 140Var.

Case 2: Offshore wind energy system integrated with the grid having power enhancement fuzzy based controller.

The DCWT system in this case is connected to the DC transmission system for offshore energy system. In this case the system is connected by a power controller which is controlled by a fuzzy logic codes. The enhancement in output active as well as reactive power is further discussed to mark the reliability of the controller in DCWT wind energy systems particularly.

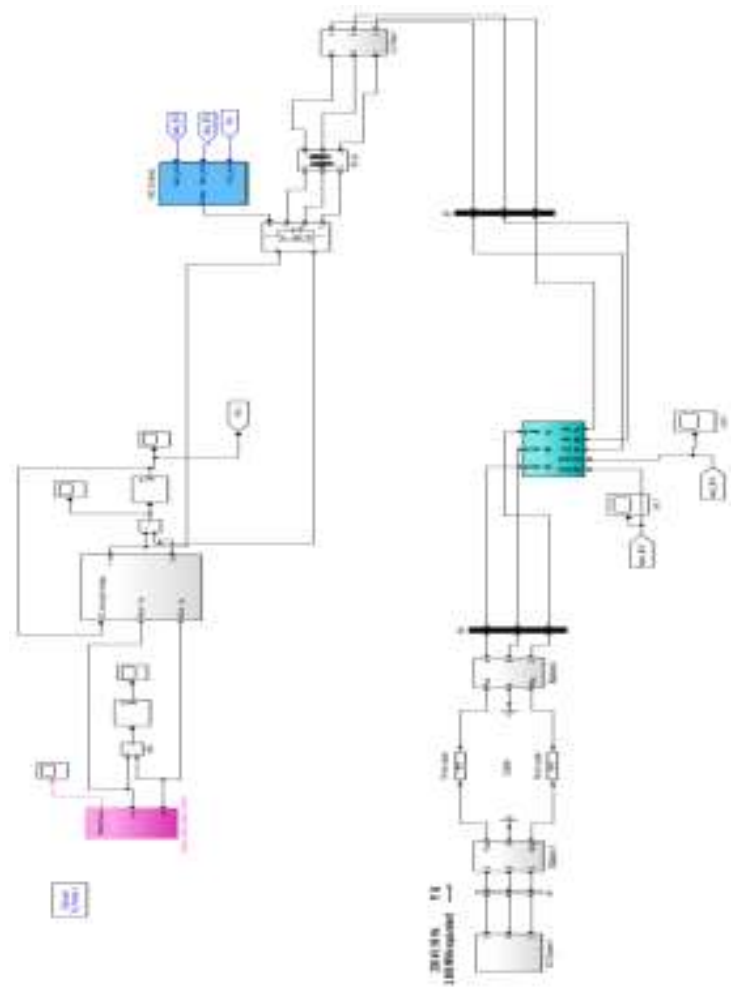

Fig. 18 Offshore wind energy system integrated with the grid having power enhancement fuzzy based controller 
The fuzzy logic control utilized in DCWT system is expected to enhance the operation of the system. A fuzzy control system is a control system based on fuzzy logic - a mathematical system that analyzes analog input values in terms of logical variables that take on continuous values between 0 and 1 , in contrast to classical or digital logic.

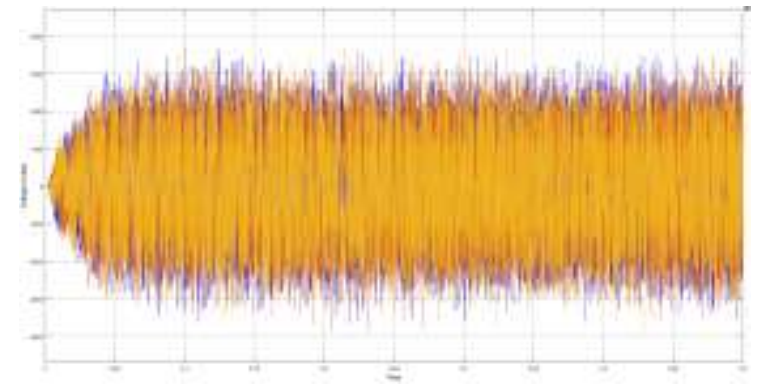

Fig. 19 Voltage Output of the system having power enhancement fuzzy based controller

In this Wind energy system in which power controller based on fuzzy logic rules is connected the voltage output is approximately $2.5 \mathrm{KV}$. This voltage output is from the system in which numerous DC wind turbine integrated and their voltage output is measured.

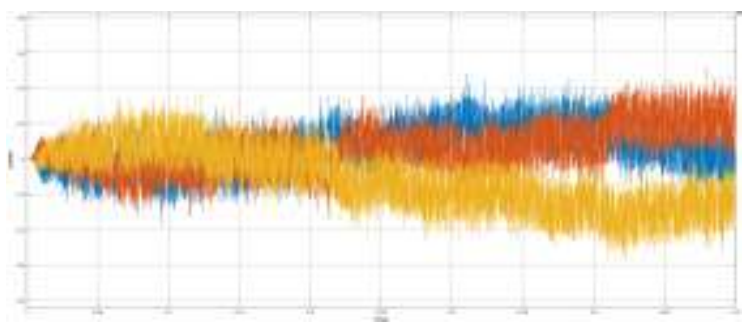

Fig. 20 Current Output of the system having power enhancement fuzzy based controller

Fig. 20 is showing current output from the DC wind turbine at the point where the power is converted from DC to AC through inverter and then the power enhancement device having fuzzy based rules is connected. The current is generated at 50 hertz which can be used for driving various kinds of loads at this point.

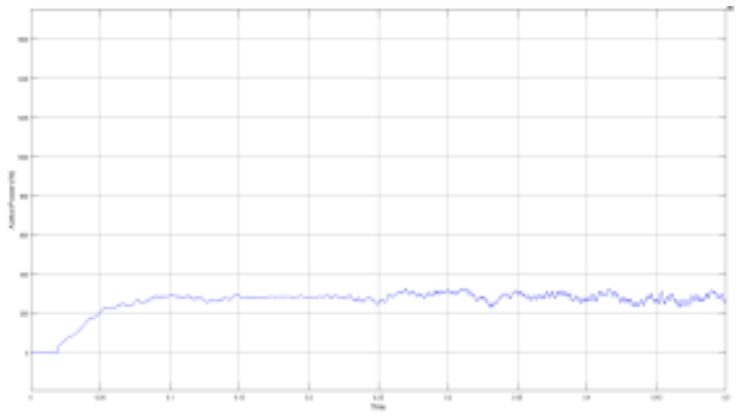

Fig. 21 Active Power Output of the system having power enhancement fuzzy based controller

The fig. 21 is showing the active power output from the system having fuzzy based controller for power enhancement. The output shows that the power has been enhanced as compared to the previous model to approximately $300 \mathrm{Watts}$.

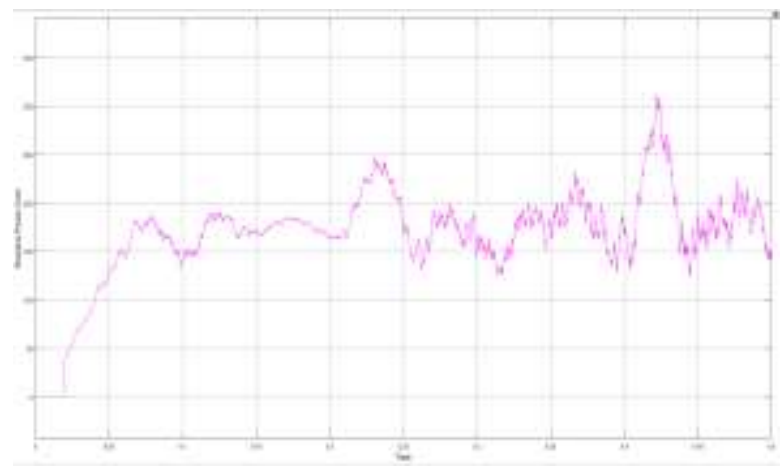

Fig. 22 Reactive Power Output of the system having power enhancement fuzzy based controller

The reactive power moves between the source and load of the circuit. Stability and reliability of electrical power system depends on reactive power management. The reactive power output from the DCWT system having power enhancement device with fuzzy based power controller was found to be approximately 150 Var.

\section{A. Validation}

Comparative analysis of the system having no power controller and wind energy system having UPFC based power flow controller is being discussed in this chapter. The active power outputs as well as reactive power outputs are being enhanced using fuzzy based control.

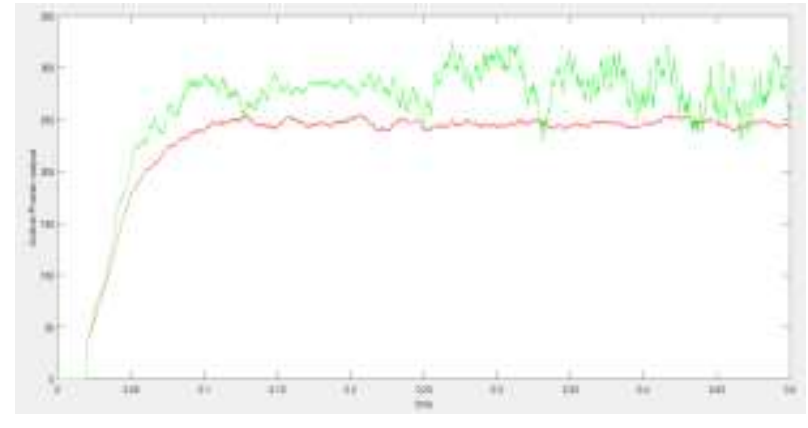

Fig. 23 Comparative analysis of active power flow control

Fig. 23 is the depicting the active power output from the two systems and their comparison is being carried out. The red graph shows the active power generated from the system having no power controller whereas the green graph is showing the active power output from the system which is also having a power controller controlled by Fuzzy Logic rules. The figure is clearly showing that the active power has been enhanced by using the controller designed having intelligent control

The active power output of the system with no power flow control is approximately $250 \mathrm{~W}$ and wind energy system with fuzzy based control is approximately $300 \mathrm{~W}$. 


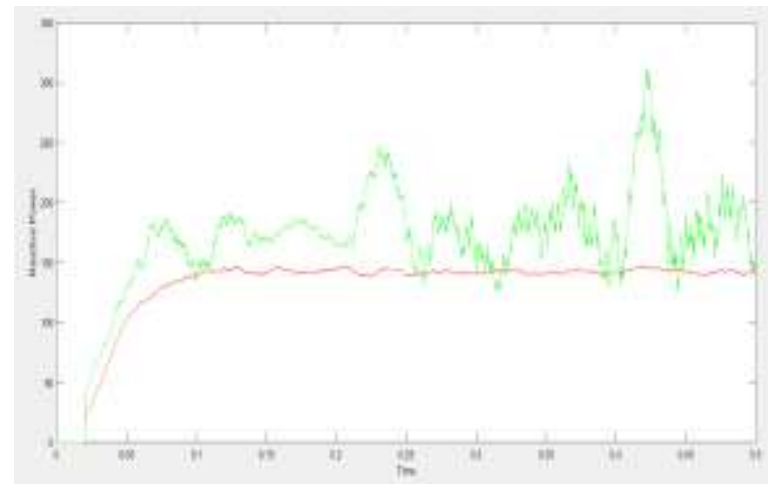

Fig. 24 Comparative analysis of Reactive power flow control

The fig. 24 shows the comparative analysis of the reactive power output from the two systems having no controller and the other word having a controller for power enhancement controlled by Fuzzy Logic rules. The power output has been found to be enhance from 140 Var to approximately 150 Var which can be used for compensation when the loads are connected.

\section{CONCLUSION}

The massive transmission of electricity in the form of DC over long distances by means of submarine cables or overhead transmission line is the high voltage direct current transmission. This type of transmission is preferred over HVAC transmission for very long distance when considering the cost, losses and many other factors. The names Electrical superhighway or Power superhighway are often used for HVDC. Offshore wind resources are abundant, stronger, and blow more consistently than land-based wind resources.

In this work a coordinated control based on Fuzzy logic for UPFC for cluster of offshore Wind turbines connected to the same HVDC connection is being implemented and analyzed. The study is targeting coordination of reactive power flow and active power flow between HVDC

Converter and the WPP cluster while providing offshore AC grid voltage control.

Following main conclusions are being drawn:

- On comparing the active power outputs from the system without any power flow control with the proposed fuzzy logic based active power control using UPFC, it was found to be that the proposed system gives $250 \mathrm{~W}$ output which is considerably more than the 300 VA output of the system without any controller.

- Also the reactive power outputs of the system has been considerably improved using the UPFC based on fuzzy logic controller from approximately 140 Var to approximately 150 Var. This depicts that system is able to drive the more reactive power load as compared to the previous model.

- The system has been integrated with the grid using long transmission DC line of $75 \mathrm{~km}$ for making it more reliable.

Thus it can be drawn from this work that while designing a power control strategy the proposed fuzzy logic based active power controller in UPFC can serve the purpose with better results in terms of active as well as reactive power. This control can also be used in hybrid systems thus making it more reliable controlling method. The system designed is also fitted to feed the nonlinear load.

Future Scope

Installing this long distance DC transmission system will be actually very fruitful because it will reduce the grid dependency. On the other hand, this system promotes green energy which is very important because all the energy sources are depleting day by day. So, people must look for new renewable sources and solar power is definitely one of the best choices in this purpose. In future work an adaptive neural network based control for improved power quality 3 phase grid integrated with nonlinear and linear loads will be designed. The expected control scheme regulates the system voltage and improves the power quality in a very effective manner.

\section{REFERENCES}

[1] Gang Shi, Jianwen Zhang "Decoupling control of series-connected DC wind turbines with energy storage system for offshore DC wind farm" June 2016 DOI: 10.1109/PEDG.2016.7527064

[2] Jianwen Zhang, Liangzhong Yao "Improved Variable Speed Control of Series-Connected DC Wind Turbines for Offshore Wind Power Collection to HVDC System" DOI: 10.1049/iet-rpg.2015.0453 March 2016

[3] Etienne Veilleux, Peter W. Lehn "Interconnection of Direct-Drive Wind Turbines Using a Series-Connected DC Grid" DOI: 10.1109/TSTE.2013.2276616 January 2014

[4] Van-Tung Phan, and Hong-Hee Lee, "Performance Enhancement of Stand-Alone DFIG Systems With Control of Rotor and Load Side Converters Using Resonant Controllers," IEEE Trans. on Ind. Appl., vol. 48, No. 1, pp. 199-210, Jan./Feb. 2012.

[5] Jiaqi Liang, Dustin F. Howard, Jose A. Restrepo, and Ronald G. Harley, "Feed forward Transient Compensation Control for DFIG Wind Turbines During Both Balanced and Unbalanced Grid Disturbances," IEEE Trans. on Ind. Appl., vol. 49, No. 3, pp. 1452-1463, May/Jun. 2013.

[6] SlavomirSeman, JoukoNiiranen, and Antero Arkkio, "Ride-Through Analysis of Doubly Fed Induction Wind-Power Generator Under Unsymmetrical Network Disturbance," IEEE Trans. on Power Syst., vol. 21, No. 4, pp. 1782-1789, Nov. 2006.

[7] JihenArbi, ManelJebali-Ben Ghorbal, IlhemSlama-Belkhodja, and LotfiCharaabi, "Direct Virtual Torque Control for Doubly Fed Induction Generator Grid Connection," IEEE Trans. on Power Electron., vol. 56, No. 10, pp. 4163-4173, Oct. 2009.

[8] Etienne Tremblay, Sergio Atayde, and Ambrish Chandra, "Comparative Study of Control Strategies for the Doubly Fed Induction Generator in Wind Energy Conversion Systems: A DSPBased Implementation Approach," IEEE Trans. on Sustainable Energy, vol. 2, No. 3, pp. 288299, Jul. 2011.

[9] Peng Zhou, Yikang He, and Dan Sun, "Improved Direct Power Control of a DFIG-Based Wind Turbine During Network Unbalance," IEEE Trans. on Power Electron., vol. 24, No. 11, pp. 2465-2474, Nov. 2009. 
[10] Gonzalo Abad, Miguel A' ngelRodr' 1 guez, GrzegorzIwanski, and Javier Poza, "Direct Power Control of Doubly-Fed-InductionGenerator-Based Wind Turbines Under Unbalanced Grid Voltage," IEEE Trans. on Power Electron., vol. 25, No. 2, pp. 442-452, Feb. 2010. 